\title{
Research on the Reconstruction Design of Hainan Characteristic B\&B Based on Regional Culture Background
}

\author{
Chunyao Zhang \\ Hainan College of Vocation and Technique
}

Keywords: regional cultural background; Hainan characteristic B\&B renovation; design research

\begin{abstract}
The current characteristic B\&B has become a popular tourist destination for tourists. How to make the characteristic $B \& B$ fully reflect the regional culture has become a difficult problem for the relevant departments. The transformation and design of the characteristic residential houses can enhance the competitiveness of regional culture. Economic development, this paper will study the specific advantages of Hainan's characteristic B\&B renovation and the problems that should be paid attention to, and provide some opinions and suggestions on how to better carry out the renovation and design of Hainan specialty B\&B.
\end{abstract}

\section{Introduction}

The people have put forward higher requirements for the characteristics of tourism and residence. The renovation and design of Hainan specialty B\&B should be carried out under the background of regional culture. The transformation of the characteristic $\mathrm{B} \& \mathrm{~B}$ should pay attention to the interior transformation of the $\mathrm{B} \& \mathrm{~B}$ and the external transformation of the $\mathrm{B} \& \mathrm{~B}$. In this process, it is necessary to strengthen the reflection of regional cultural characteristics. Next, we will introduce the specific advantages of Hainan's characteristic residential renovation and design work, and introduce several ways to better carry out the transformation and design work of the characteristic $\mathrm{B} \& \mathrm{~B}$. Method, the development of the characteristic B\&B is doing its best.

\section{The specific advantages of Hainan's characteristic B\&B renovation based on regional culture background}

\subsection{Conducive to the protection of material cultural heritage within the scope of regional} culture

The characteristic residential houses are not only popular tourist destinations for tourists, but also the material and cultural heritage of Hainan's rich regional cultural characteristics. It is mainly used by local residents in Hainan to use their own houses, combined with the main characteristics of local culture, natural landscapes and major production methods. Providing a comfortable environment for tourists to live in. On the other hand, the homestay is the main environment for visitors to experience the cultural differences between Hainan's local culture and other regions. It can fully reflect the local cultural characteristics of Hainan and also feedback the current tourists. The aesthetic experience of consumption represents the pursuit of tourists for this kind of living conditions, and the transformation and design of Hainan's characteristic residential houses can reflect the local folk customs of Hainan in a wider scope, and introduce the tourists who come to live. The regional culture of Hainan has deepened the impression of Hainan and other areas. The characteristic residential houses are generally attached to the tourist attractions in Hainan and other places. There are many tourists, which can cater to the needs of tourists for tourism and play, and enhance the tourist experience. Conducive to the protection of material cultural heritage within the scope of regional culture.

\subsection{Enhancing the competitiveness of culture to help economic development}

In addition to the advantage of protecting the material and cultural heritage within the regional culture, improving the competitiveness of culture to help economic development is also a major advantage of the transformation of Hainan's characteristic B\&B. The interior spatial transformation 
of characteristic residential houses and the external form of buildings After the transformation and other comprehensive transformation work, Hainan's characteristic residential houses will further deepen the regional cultural characteristics of the region, fully exploit the humanistic values contained in Hainan's characteristic B\&B, and transform and design them to make Hainan characteristics As a growth point of economic development, B\&B, by using Hainan specialty B\&B as a new driving force for economic development, can promote the development of tourism in Hainan and other regions, making tourism a business card for urban development in Hainan, and improving regional culture in the fierce competition in tourism. The status of the environment, thereby enhancing the cultural competitiveness of the hotel to help economic development ${ }^{[1]}$.

\section{Problems that should be paid attention to during the renovation and design of Hainan specialty house}

\subsection{Spatial transformation of the interior of the property}

The first problem that should be paid attention to during the renovation and design of Hainan characteristic house is that for the spatial transformation of the interior of the hotel, the spatial transformation of the hotel should be based on the background of regional culture, and the interior of the hotel will be built into a collection of various functional facilities. It is also necessary to carry out spatial transformation of transportation space, accommodation space and public entertainment space, and make full use of the overall space of the hotel. Among them, the spatial transformation of transportation should be carried out in accordance with the principle of convenient transportation and aesthetics. The central axis is symmetrical to improve the aesthetics of the traffic space. The center of the courtyard is the central axis, and the remaining space on both sides is used as the accommodation space to ensure the smooth flow of traffic on both sides. For the accommodation space, the Hainan specialty hotel should focus on improving its comfort and Intimate, considering the wet and rainy weather in Hainan, the accommodation space should be avoided in the cold shades and hot places, providing visitors with a comfortable accommodation experience, and gardens and corridors can be arranged around them for privacy design., you need to ensure that its related activities can avoid the sight of the rest of the people, but also need to protectIt can be used to appreciate the beautiful scenery inside the residential buildings, and for the spatial transformation of the public entertainment space, it can be placed in the central location of the residential buildings to ensure that its public entertainment space is wide enough to provide visitors with plenty of entertainment space. Some modern games and other facilities can be added to facilitate the entertainment activities of tourists. Finally, through the transformation of Hainan's characteristic residential houses, the original courtyard layout can be preserved to fully reflect the regional cultural characteristics of the region. The interior of the residential building was transformed, and the trees were used to provide a cool area to separate the areas to ensure that the layout of each area was convenient and reasonable.

\subsection{Modification of the exterior of the building}

In addition to the spatial transformation of the interior of the hotel, the transformation of the exterior of the building is also a problem that needs to be paid attention to during the renovation and design process. First, the external architecture of the hotel and the surrounding environment should be considered. According to the standard of accommodation, especially for the lighting and ventilation, it is necessary to carry out key renovations to ensure that the hotel has good lighting and smooth ventilation. Secondly, for the transformation of Hainan characteristic hotel, it should be The architectural concept of the $B \& B$ and its unique architectural rules are summarized. Only by fully observing the rules of the $\mathrm{B} \& \mathrm{~B}$ building can avoid the unreasonable construction of the $\mathrm{B} \& \mathrm{~B}$, and ensure that the $B \& B$ can carry out the transformation of the appearance form in the functions of plane function, basic shape and some decoration. There are many ethnic groups in Hainan, so the appearance of the $\mathrm{B} \& \mathrm{~B}$ in each area reflects the cultural characteristics of each ethnic group. Therefore, when morphological transformation of the exterior building of the $\mathrm{B} \& \mathrm{~B}$, the cultural 
characteristics of each ethnic group should be combined with the artistic features. Reflecting the regional cultural characteristics, it can also enhance the artistic characteristics of the hotel and The humanistic value is fully reflected. Finally, it is necessary to meet the needs of tourists for the use function and aesthetic appearance of the hotel. Pay attention to the overall appearance and design details in terms of appearance, so as to fully cater to the public's aesthetic concept and consumer culture ${ }^{[2]}$.

\section{How to better carry out the renovation and design work of Hainan specialty hotel}

\subsection{Renovation and design of the characteristic $B \& B$ from the overall structure}

In order to better carry out the transformation and design work of Hainan's characteristic residential houses, the first step is to transform and design the characteristic B\&B from the overall structure. In the process, the $\mathrm{B} \& \mathrm{~B}$ renovation and design department should carefully understand the development of tourism in Hainan. Relevant planning schemes, combined with the planning measures of the land administration department of Hainan Province for the land area where the homestay is located, and the principle of reducing the impact of the transformation and design process of Hainan characteristic homes on the ecological environment as much as possible, and the indoor and external forms of characteristic residential houses. The transformation of space, adapting to local conditions, fully excavating the regional cultural characteristics and humanistic values of Hainan's characteristic residential houses, arranging the common plants and flowers in the area around the $\mathrm{B} \& \mathrm{~B}$, providing visitors with a comfortable viewing and accommodation experience, setting key renovations and The design module, especially for the beautiful natural environment, the cultural characteristics are obvious and the infrastructure is relatively sound, as the key renovation area of the B\&B, with the key points, the key renovation and design work of some B\&Bs will drive the development of the whole $\mathrm{B} \& \mathrm{~B}$ in Hainan, and according to the tourism in Hainan. The actual situation of the industry development, the people in the areaThe renovation and design process of the accommodation will be rationally planned, taking into account the impact of the renovation of the hotel as an ecological environmental protection work and the cost and cost of the renovation of the hotel, combined with the current situation of economic development in Hainan, as much as possible to reduce the cost of transformation and improve The aesthetics and practical effects of the renovation and design of the $\mathrm{B} \& \mathrm{~B}$, from the perspective of the overall structure, the transformation and design of the characteristic $\mathrm{B} \& \mathrm{~B}$, grasping the overall situation of the $\mathrm{B} \& \mathrm{~B}$ renovation, thus driving the development of the $\mathrm{B} \& \mathrm{~B}$ in Hainan ${ }^{[3]}$.

\subsection{Clarify the status of regional culture and spiritual civilization wealth in the process of home improvement}

Another measure that needs to be taken is to clarify the status of regional culture and spiritual civilization in the process of home improvement. Hainan's characteristic B\&B is the embodiment of regional cultural characteristics and spiritual civilization. Therefore, the transformation and design of Hainan characteristic B\&B should be Based on the characteristics of regional culture and the wealth of spiritual civilization, we will establish a regional culture as the core, and transform the exterior style, interior decoration, dining and entertainment facilities of the characteristic B\&B around this core, and local products such as coconut in Hainan. As the main style of interior decoration, coconut can also be promoted as a special product of the region to tourists, and the concept of innovation is constantly innovated to reflect the folk customs of Hainan. For example, the products sold in specialty stores can be affixed to the unique labels of Hainan. Registration can be The commercial logo embodying the cultural characteristics of the area and fully applied to the interior decoration and dining and entertainment facilities of the hotel, so that visitors can fully enjoy the entertainment and accommodation experience of Hainan's characteristic B\&B, and can deepen their impression of Hainan B\&B. , the home improvement work can be divided into areasIn the process of its transformation, it reflects the concept of systemization and conceptualization, systematically upgrades and transforms the divided transportation space, accommodation space and dining and entertainment space, so that it meets the requirements of current tourists for characteristic residential houses, and transforms the entire residential building. The design process is vibrant and has a sustainable space. 


\subsection{Innovation B\&B renovation concept and design method}

In addition to the transformation and design of characteristic residential houses from the overall structure and the determination of the status of regional culture and spiritual civilization in the process of home improvement, the innovative $\mathrm{B} \& \mathrm{~B}$ renovation concept and design method also promotes the smooth transformation of its design and design work. Important measures, the relevant departments can carry out the renovation of the hotel in terms of the choice of building materials and the innovation of the design of the hotel.

In the choice of building materials, we can consider the use of new building materials. The architecture of the characteristic B\&B is a highlight of attracting tourists. Therefore, without changing the appearance of the building, new building materials can be used through the building materials. To illustrate the humanistic value behind the $B \& B$, and to show the regional cultural characteristics of the traditional $\mathrm{B} \& \mathrm{~B}$, the reformers can choose the building materials that are easily available in Hainan, such as wood, to transform the dwellings. The patterns and textures of the folk customs in the area can be portrayed on the wood. If necessary, the color can be applied to meet the aesthetic concept of the visitor, thereby improving the aesthetics.

On the other hand, in the innovation of the design of the hotel, the designers need to understand the current advanced concept of the building, and combine the folk customs and climatic conditions in Hainan to innovate the design concept of the hotel, so that it fully reflects the area. The architectural style can also cater to the development trend of the hotel building industry. For the part of the cultural characteristics of the hotel building, the second part of the design and innovation of its performance and performance style, highlighting the expression and style of the building's architectural features, and the surrounding environment In addition, the designer should fully consider the impact of the innovative $\mathrm{B} \& \mathrm{~B}$ architectural concept on the surrounding ecological environment, respecting nature and respecting humanity as the design principle, reducing the damage to the biological migration path and the natural environment, and being as close as possible to the local ecological environment. It also effectively designs the transportation space, accommodation space and leisure and entertainment space of the hotel, providing visitors with a comfortable environment and living experience, thus truly reflecting the value of the building ${ }^{[4]}$.

\section{Summary}

The renovation and design work of Hainan Characteristic B\&B should be carried out under the background of regional culture. Its smooth implementation is conducive to protecting the material and cultural heritage within the regional culture and enhancing the competitiveness of the culture. Persons involved in the renovation and design of the B\&B should fully consider The local customs and customs, combined with the status quo of economic development in the region, innovate the architectural design concept of $\mathrm{B} \& \mathrm{~B}$, clarify the status of regional culture in this process, and contribute more to the transformation and design of the hotel in line with the principle of protecting the ecological environment and saving costs. .

\section{References}

[1] Xu Ya, Xie Le. Research on the Design of B\&B Space under the Background of Regional Culture[j]. Building Materials and Decoration, 2017(36).

[2] Chen Zhuo. Research on the renovation design of rural homes based on regional culture background [j]. Shanxi Architecture, 2018(2): 1-2.

[3] Anonymous. Design of B\&B Space in the context of regional culture [j]. Residential and Real Estate, 2018, 516(30):100.

[4] Anonymous. B\&B research highlighting regional cultural characteristics [j]. Beauty and Times: Creativity (Part 1), 2018, 760(08): 37-39. 